\title{
Effectiveness of glycerol-monooleate in high-performance polymer tribo-systems ${ }^{\dagger}$
}

\author{
Shaoli Jiang, ${ }^{1,2}$ Chengqing Yuan, ${ }^{2}$ Janet S. S. Wong ${ }^{1 *}$
}

${ }^{1}$ Department of Mechanical Engineering, Imperial College London, London SW7 2AZ, UK

${ }^{2}$ Key Laboratory of Marine Power Engineering \& Technology (Ministry of Transport), Wuhan University of Technology, Wuhan 430063, P.R. China

${ }^{*}$ Corresponding author email: j.wong@imperial.ac.uk (J.S.S. Wong)

${ }^{\dagger}$ All work was conducted at Imperial College London

\begin{abstract}
High performance polymers possessing superior mechanical properties may replace metal components and improve machine efficiency. Successful replacement, however, relies on the compatibility of these polymers with current engineering systems, including lubricants and their additives. This study examines the compatibility of two high performance polymers, polyetheretherketone (PEEK) and polyamide-imide (PAI), with glycerol monooleate (GMO), an organic friction modifier (OFM) commonly used in steel-steel rubbing contacts. Friction tests were conducted with a ball-on-disc geometry in reciprocating motion at $100^{\circ} \mathrm{C}$ in polyalphaolefin (PAO) base oil. GMO reduces friction in polymer-steel and polymer-polymer contacts. When steel is involved, the use of GMO and oleic acid (OA) give similar friction coefficients. Since OA is believed to be a hydrolyzed product of GMO in steel-steel contacts, our results show that the interaction of OA with steel controls friction in polymer-steel contacts when GMO is the additive. Results from FTIR and Raman spectroscopies show that steel surfaces contain little to no polymeric materials, nor iron oxides after rubbing against polymers in GMO- and OA- containing PAO. This supports OFM layers are formed on steel surfaces. These OFM layers prevent polymer transfer layer formation and possibly protect steel surfaces from oxidation. Our results show that using OFM that interacts strongly with steel can, contrary to dry friction, eliminate the need of polymeric transfer film on steel for achieving low friction in polymer-steel contacts.
\end{abstract}

\section{KEYWORDS:}

glycerol monooleate, friction modifier, high-performance polymers, polyetheretherketone, polyamide-imide.

\section{INTRODUCTION}

Reducing wear and friction in machines are important for reducing energy consumption and $\mathrm{CO}_{2}$ emissions. ${ }^{1}$ Adding friction modifiers in lubricants is a common friction reduction strategy, especially in the boundary and mixed lubrication regimes where asperity-asperity contacts between rubbing surfaces are frequent. Organic friction modifiers (OFMs) are amphiphilic molecules, with polar head groups and aliphatic tails. Their effectiveness is generally attributed to the formation of OFM adsorbed films, resulting in a low shear, protective layer on rubbing surfaces. $^{2-3}$ The first OFMs are fatty acids which can be found in natural oils. Since it may corrode metal surfaces, by the 1930s, they have been replaced by amphiphiles such as esters or by complex organo-acid-based compounds, like phthalic anhydride. ${ }^{4}$ 
Glycerol-monooleate (GMO) is an oleochemical which is an effective OFM in steel-steel contacts. It has been suggested that GMO, its hydrolysis products (oleic acid and glycerol), and water formed micelles or aggregates in n-heptane and toluene under both static and shear conditions. $^{5-7}$ These micelles adsorbed on the surface. The nature of the GMO adsorbed layer is surface dependent. For a steel-steel contact, it has been suggested that the adsorbed layer consists of hydrolysis products of GMO ${ }^{8}$ When diamond-like-carbon (ta-C DLC) coated steel surface was rubbed against steel, it is suggested that the formation of $\mathrm{OH}$ species due to the degradation of GMO may react with the carbon dangling bonds on the DLC surface, resulting in a low friction surface. ${ }^{9}$ Like other OFMs, higher concentrations of GMO results in higher surface adsorption, and hence lower friction coefficient. ${ }^{10}$

Apart from managing friction, energy efficiency of machines can be improved by using lightweight materials. Polymers have lower density than metal. In the case of high-performance polymers (HPPs), they have reliable mechanical and tribological performance even at relatively high temperatures and stresses. HPP components may potentially replace metal components in some applications, such as gears, turbines and cam sprockets. ${ }^{11}$ Recently polymer engines with composite parts have been designed with half the weight of metal engines. One of them was in sports car races over two seasons. ${ }^{12-14}$

Among HPPs, polyetheretherketone (PEEK) $)^{15-16}$ and polyamide-imide (PAI) ${ }^{17-18}$ have been studied extensively for their tribological performance. Research so far has been focused on nonlubricated (dry) conditions, in which PEEK-steel and PAI-steel contacts at room temperature have friction coefficients in the range of $0.25-0.3{ }^{19}$ and $0.3-0.44{ }^{20}$ respectively. This is much lower than that in steel-steel contacts (higher than 0.7$)^{11}$. It is believed that polymeric materials were transferred to the steel counterface and the resulting transfer layer was responsible for reduction in friction and wear. ${ }^{18-19}$ Note that the formation of a polymeric transfer layer may be related to the glass transition or melting point of the polymer. ${ }^{20}$

To further reduce friction in polymer-steel contacts, lubricants may be used. This option has gained attention and some of the recent results are summarized in Table 1. Introducing lubricants may bring new challenges to using polymer-steel rubbing contacts, including the hindrance of polymeric transfer film formation. On the other hand, improvements of loadbearing capability and frictional heat removal may occur.

Table 1 Some literatures on performance of lubricated polymer-polymer or polymer-metal contacts.

\begin{tabular}{|l|l|l|}
\hline Materials & Lubricant & Results \\
\hline $\begin{array}{l}\text { Pins of polyamide (PA), ultra- } \\
\text { high molecular weight } \\
\text { polyethylene (UHMWPE), and } \\
\text { their blend (PA/UHMWP) were } \\
\text { rubbed against 316 stainless steel } \\
\text { discs. }\end{array}$ & $\begin{array}{l}\text { Water based } \\
\text { emulsion } \\
\text { (water/soluble oil } \\
=95 / 5)\end{array}$ & $\begin{array}{l}\text { Friction of PA decreased by } \\
\text { blending with UHMWPE due to a } \\
\text { transfer film. } .^{21}\end{array}$ \\
\hline $\begin{array}{l}\text { PEEK lined pads were rubbed } \\
\text { against a steel shaft. }\end{array}$ & $\begin{array}{l}\text { ISO VG32 } \\
\text { mineral oil }\end{array}$ & $\begin{array}{l}\text { PEEK lined pads had higher load } \\
\text { capability than Babbitt lined pads } \\
\text { and they did not show signs of }\end{array}$ \\
\hline
\end{tabular}




\begin{tabular}{|l|l|l|}
\hline & & $\begin{array}{l}\text { bearing damage or film } \\
\text { breakdown. There was no } \\
\text { significant difference of energy } \\
\text { loss between the two pads. }{ }^{22}\end{array}$ \\
\hline $\begin{array}{l}\text { PEEK and PEEK composite } \\
\text { plates with fillers including short } \\
\text { carbon fibers, solid lubricants and } \\
\text { ceramic particles were rubbed } \\
\text { against 100Cr6steel rings. }\end{array}$ & $\begin{array}{l}\text { Ultra-low sulfur } \\
\text { diesel and engine } \\
\text { oil }\end{array}$ & $\begin{array}{l}\text { A small addition of diesel } \\
\text { significantly increased friction and } \\
\text { wear of PEEK-steel contacts since } \\
\text { it hindered the formation of } \\
\text { transfer film. Friction and wear } \\
\text { were then lowered as the amount } \\
\text { of diesel increased. }{ }^{23}\end{array}$ \\
\hline $\begin{array}{l}\text { Polyphenylenesulfide (PPS) } \\
\text { Polyamide 66 (PA66), and } \\
\text { polytetrafluoroethylene (PTFE) } \\
\text { pins were rubbed against discs of } \\
\text { the same materials. }\end{array}$ & Liquid paraffin & $\begin{array}{l}\text { Applied PV value had little effect } \\
\text { on the tribological behaviors of } \\
\text { lubricated contacts. Friction was } \\
\text { reduced since lubrication reduced } \\
\text { the amount of frictional heat. }{ }^{16}\end{array}$ \\
\hline $\begin{array}{l}\text { PTFE-based composites were } \\
\text { rubbed against 45 carbon steel. }\end{array}$ & $\begin{array}{l}\text { Glycerol, } \\
\text { triethanolamine } \\
\text { and gasoline } \\
\text { engine lubricant } \\
\text { oil. }\end{array}$ & $\begin{array}{l}\text { Wear and transfer of PTFE } \\
\text { composite onto steel counterface } \\
\text { were significantly reduced } \\
\text { compared with non-lubricated } \\
\text { conditions. }{ }^{15}\end{array}$ \\
\hline
\end{tabular}

Since the same lubricant is usually used for the whole multi-component engineering system, the success of implementing polymeric parts to replace existing metal parts will partly depend on whether polymeric parts will be effective in lubricants designed for steel. While works like those in Table 1 have provided interesting insights on lubricated polymer-polymer or polymersteel contacts, information on roles of individual constituents in lubricants is lacking. This is particularly important for surface active additives such as friction modifiers. In this work, the performance of PAI-steel and PEEK-steel contacts in GMO containing lubricants at $100^{\circ} \mathrm{C}$ was investigated and compared to polymer-polymer and steel-steel contacts. Polyalphaolefin (PAO4), a synthetic oil, was used here as the base oil. The objectives of this work are firstly to examine if GMO is an effective friction modifier in a polymer-steel and polymer-polymer contacts; and secondly the effect of the GMO on the formation of polymeric transfer layer on steel.

\section{EXPERIMENTAL}

\subsection{Test materials}

Glycerol monooleate $\left(\mathrm{GMO}, \geq 99.0 \%\right.$, molecular weight $\left.=356.54 \mathrm{~g} \mathrm{~mol}^{-1}\right)$ and oleic acid $(\mathrm{OA}$, $99.0 \%$, molecular weight $=282.46 \mathrm{~g} \mathrm{~mol}^{-1}$ ) were purchased from Sigma-Aldrich (see their molecular structures in Figure 1). PAO4, with a kinematic viscosity of $3.9 \mathrm{cSt}$ at $100^{\circ} \mathrm{C}$, was from SK Lubricants Co., Ltd. Four lubricants were prepared: PAO4 base oil, PAO4+GMO (1 $\mathrm{wt} \%, 0.0023 \mathrm{~mol} / \mathrm{L})$ and two PAO4+OA of different concentrations of OA $(0.0029 \mathrm{~mol} / \mathrm{L}$ and $0.0023 \mathrm{~mol} / \mathrm{L}$ ). They have similar viscosities (see Supplementary Information SI 1). 
(a)<smiles>CN(C)C(=O)c1ccc2c(c1)C(=O)N(C(C)(C)C)C2=O</smiles>

(c)<smiles>CCCCCCCC/C=C\CCCCCCCC(=O)OCC(O)CO</smiles>

(d)

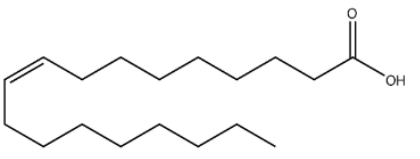

(e)

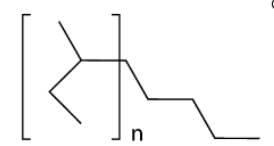

Figure 1 Molecular structures of (a) Polyamide imide (PAI), (b) Polyetheretherketone (PEEK), (c) glycerol monooleate (GMO), (d) oleic acid (OA), and (e) Polyalphaolefin (PAO) base oil.

PEEK and PAI samples (see their molecular structures in Figure 1) were provided by Victrex plc and Hoerbiger Inc. USA. Steel balls and steel discs were through-hardened AISI 52100 steel from PCS instruments. All discs have a diameter $10 \mathrm{~mm}$ with thickness $3 \mathrm{~mm}$; and the diameter of balls is $6 \mathrm{~mm}$. Surface roughness of samples was obtained by confocal microscopy (Olympus Optical Co., Ltd). Other material properties were acquired from manufactures' materials properties guides. ${ }^{21-22}$ Properties of the samples are listed in Table 2.

Table 2. Material properties of rubbing samples

\begin{tabular}{|c|c|c|c|}
\hline & PAI & PEEK & 52100 Steel \\
\hline $\begin{array}{c}\text { Poisson Ratio } \\
\text { GPa }\end{array}$ & 0.45 & 0.38 & 0.3 \\
\hline $\begin{array}{c}\text { Tensile modulus, } \\
\mathrm{GPa}\end{array}$ & 4 & 3.5 & 200 \\
\hline $\begin{array}{c}\text { Compressive strength, } \\
\mathrm{MPa}\end{array}$ & $131\left(100^{\circ} \mathrm{C}\right)$ & $70.32\left(120^{\circ} \mathrm{C}\right)$ & 210 \\
\hline Tensile strength, $\mathrm{MPa}$ & $137.36\left(100^{\circ} \mathrm{C}\right)$ & $62.05\left(100^{\circ} \mathrm{C}\right)$ & $0.052 \pm 0.0138 /$ \\
\hline $\begin{array}{c}\text { Surface roughness } \\
\text { Sa }(\mu \mathrm{m}) \\
\text { Ball / Disc }\end{array}$ & $2.287 \pm 0.428 /$ & $3.169 \pm 0.272 /$ & $0.004 \pm 0.001$ \\
\hline Hardness & $8.94 \pm 0.038$ & $0.799 \pm 0.023$ & $835 \mathrm{Hv}$ \\
\hline $\begin{array}{c}\text { Glass transition } \\
\text { temperature }{ }^{\circ} \mathrm{C}\end{array}$ & 275 & $84.5 \mathrm{Shore} \mathrm{D}$ & 143 \\
\hline
\end{tabular}

Prior to tests, all samples were cleaned by using toluene in a sonication bath for 10 minutes, followed by rinsing with isopropanol. Then all balls and discs were dried by a dry cloth before the tests. Isopropanol (analytical reagent grade,99.8\%, Fischer Chemicals) and toluene (analytical reagent grade, 99.8\%, Fischer Chemicals) were used as received. PEEK and PAI have good chemical resistance to these cleaning agents according to manufactures' materials properties guide. 


\subsection{Friction measurements}

Friction measurements were conducted using a high frequency reciprocating rig (HFRR, PCS Instruments Ltd., Acton UK). The HFRR loads a 6-mm diameter ball against a stationary flat disc immersed in a lubricant at a controlled temperature. A targeted average sliding speed is achieved by adjusting the frequency of the reciprocating motion of the ball and its stroke length. The stroke length was set at $1 \mathrm{~mm}$ at $100 \mathrm{~Hz}$, corresponding to an average sliding velocity of $0.2 \mathrm{~m} / \mathrm{s}$. The applied loads were 2, 6 and $9 \mathrm{~N}$ and the corresponding initial average contact pressures based on Hertzian contact mechanics ${ }^{1}$ are listed in Table S2-1 (see supplementary information SI 2). Test temperature was set at $100^{\circ} \mathrm{C}$, as measured by a thermocouple near the disc specimens. The test duration was 60 minutes. The thickness of the lubricant film in the contact can be estimated using Hamrock and Dowson's regression equations for elliptical contacts. ${ }^{24}$ The lambda ratio, defined as the lubricant film thickness divided by the combined root mean square surface roughness of the two rubbing surfaces, calculated using the maximum speed at mid-stroke was below 0.1 for all cases. Hence all contacts were in the boundary lubrication regime. Friction coefficient was output at $1 \mathrm{~Hz}$. The friction coefficients reported in this work are averages of at least three tests.

\subsection{Surface Analysis}

Surfaces of steel balls and polymer discs were observed using optical microscopy (Hirox RH2000 and confocal microscopy (Olympus OLS5000 LEXT Confocal microscope). Wear volume and profiles of wear tracks on polymer discs, and surface roughness of wear scars on steel balls were obtained from these images.

Fourier transform infrared Spectroscopy (FTIR, Spectrum 100, Perkin Elmer, USA) and Raman spectroscopy (HORIBA Labram HR Evolution) with a $785 \mathrm{~nm}$ laser was used to obtain chemical information of rubbing surfaces. Each FTIR spectrum was obtained by integrating 100 scans performed between $500 \mathrm{~cm}^{-1}$ and $3500 \mathrm{~cm}^{-1}$ at a wavenumber resolution of $4 \mathrm{~cm}^{-1}$. Raman spectra were obtained from 20 scans of $1 \mathrm{~s}$ each between $200 \mathrm{~cm}^{-1}$ and $2000 \mathrm{~cm}^{-1}$ using a $20 \times$ objective. Before the measurements, samples were cleaned with toluene and isopropanol, and then were dried by a dry cloth. Spectra of PAO4, PAO+GMO and a dry, clean steel surface were shown in Figure S3-1 (see SI 3). There is no distinct difference between spectra of tested lubricants, probably due to the relatively low concentration of GMO used in this study.

\section{RESULTS AND DISCUSSION}

\subsection{Friction of polymer-steel tribo-pair}

Average friction coefficients (COFs) of PAI-steel (open symbols) and PEEK-steel (closed symbols) contacts lubricated with PAO+GMO (triangles) and PAO (circles) are presented in Figure 2 (see Figure S4-1 in SI4 for friction curves).

COFs of steel-steel contacts in PAO is about 0.14 (pluses, Figure 2), which agrees with the literature. ${ }^{25}$ Adding GMO into PAO reduces its friction (crosses, Figure 2) to a range as seen in 
polymer-steel contacts (circles and triangles) experiencing the same applied loads. It may be due to the higher contact pressure experienced by the steel-steel contact.

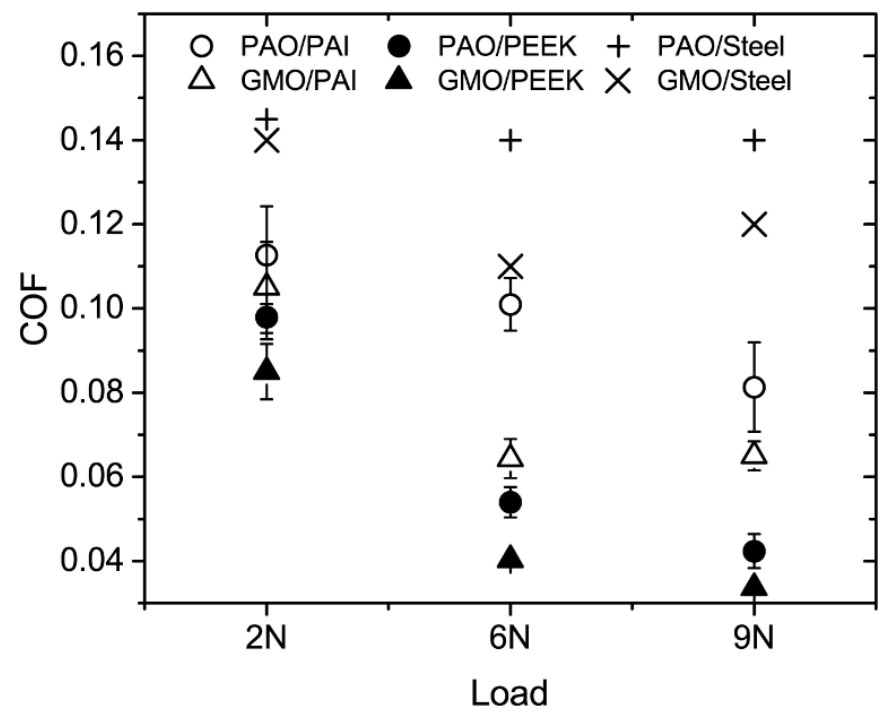

Figure 2 Steady state friction coefficients of steel ball-polymer (PEEK - solid symbols and $\mathrm{PAI}$ - open symbols) discs contacts lubricated by PAO4 (circles) and PAO+GMO (triangles) are compared to those from steel-steel contacts (pluses and crosses).

When rubbed against a steel ball, PEEK (solid symbols) gives lower friction than PAI (open symbols) in both PAO+GMO and PAO. This is similar to what has been observed in nonlubricated conditions, where the friction coefficients of PEEK-steel contacts (between 0.22 and $0.3^{19}$ ) are lower than those of PAI-steel contacts (between 0.3 and $0.45^{15}$ ). As our tests were conducted in the boundary lubrication regime, substantial polymer-steel contacts at the asperity level were expected. Hence it is not surprising that our results follow the same trend as those of non-lubricated result.

For all polymer-steel contacts, average friction coefficients decrease with increasing applied loads. Similar observations have been reported in air-cooled, ${ }^{28}$ water lubricated ${ }^{20}$ and dry conditions. ${ }^{29}$ Due to viscoelastic deformations of PEEK and PAI under load, ${ }^{3}$ friction coefficient $\mu$ and nominal applied load $W$ follow a power-law equation $\mu=\mathrm{C} W^{(n-1)}$, where $\mathrm{C}$ and $n$ are constants. The exponent $n$ is close to $1 / 3$ at low load, indicating elastic deformation; ${ }^{30}$ and close to $2 / 3$ at high load, showing a transition from visco-elastic to plastic deformation. ${ }^{31}$ Thus, as the load $W$ increases, $\mu$ decreases more slowly.

Adding GMO in PAO (triangles) reduces friction coefficients in both PAI-steel and PEEK-steel contacts. The effect at $2 \mathrm{~N}$ is small possibly due to limited asperity contacts at low loads. As the load increases, so as real contact area and the use of GMO gives rise to more significant friction reduction in both contacts. This shows that GMO is an effective friction modifier in polymer-steel contacts and suggests that GMO boundary films may have formed on either or both rubbing surfaces.

For most polymer-steel contacts, surface damage on polymer discs is minor. Wear tracks on polymer discs can only be identified at $9 \mathrm{~N}$. Images of wear tracks on polymer discs (dash 
rectangles) as well as wear scars on steel balls (dashed circles), together with their cross-section profiles (black and red respectively) are shown in Figure 3. Arithmetic average roughness (Ra) of worn surfaces are also provided. Adding GMO into PAO results in rougher polymer wear tracks and wear scars of steel balls. Fry et al. ${ }^{35}$ has made similar observations in steel-steel contacts with the use of effective OFMs. It was attributed to the ability of OFM-adsorbed layers to preserve the rough surface topography created when friction was the highest at the initial stage of the test. ${ }^{35}$ This may explain why $\mathrm{PAO}+\mathrm{GMO}$ gives lower friction despite having rougher contact surfaces than that tested with neat PAO. As scratches are formed on rubbing surfaces, the polar GMO molecules may be forced into crack tips and expand these cracks. ${ }^{36}$
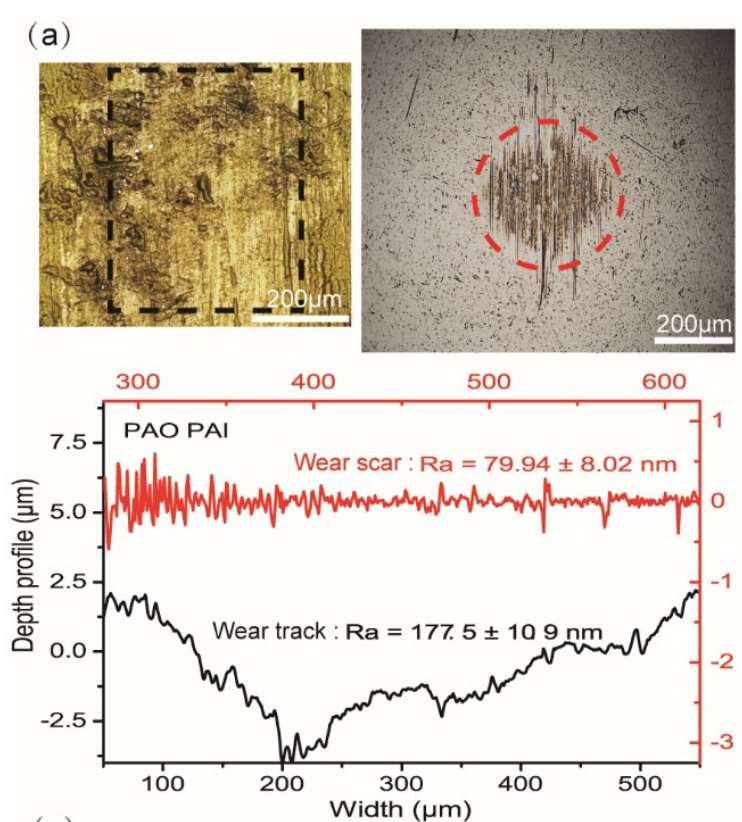

(c)
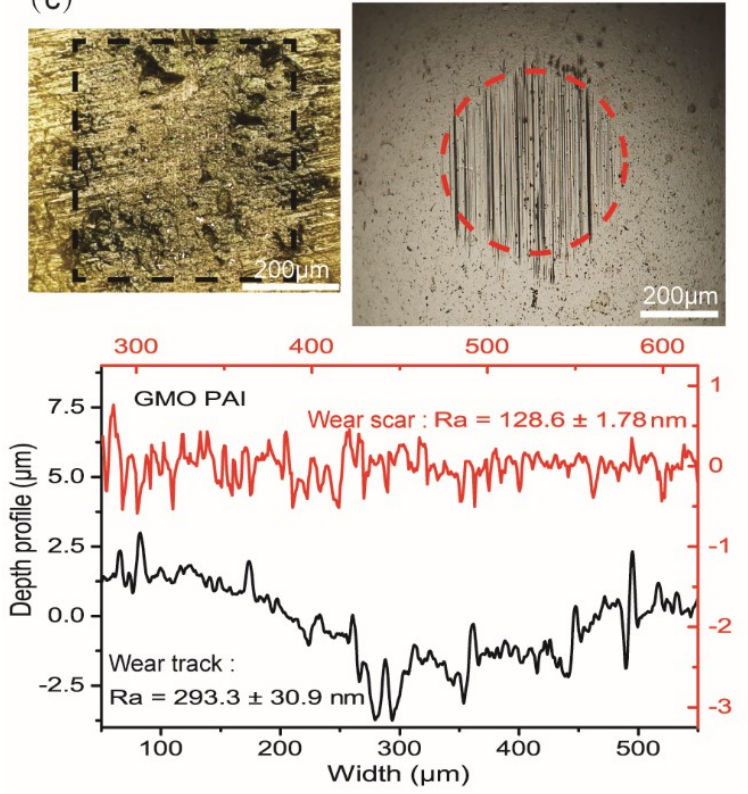
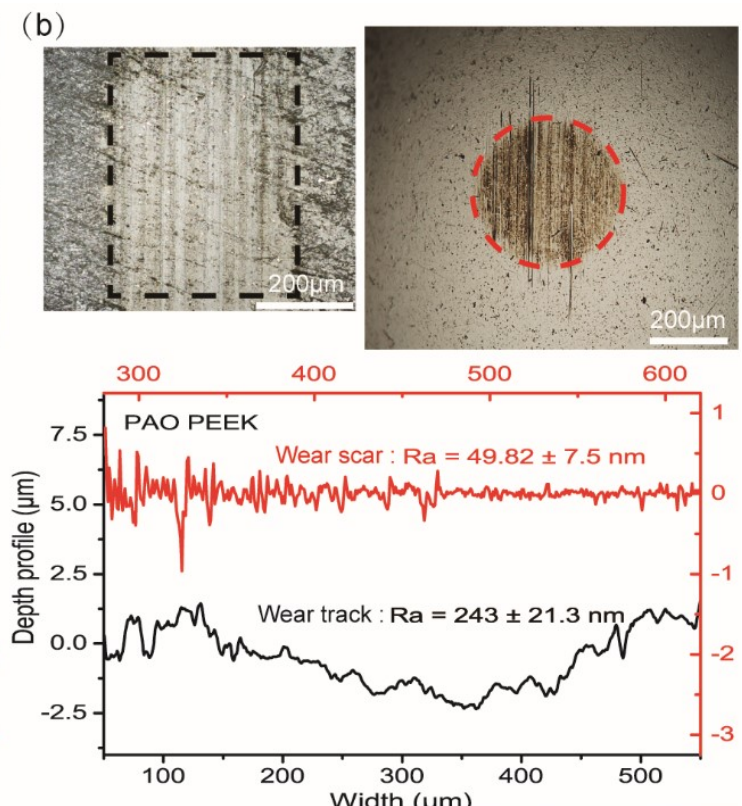

(d)
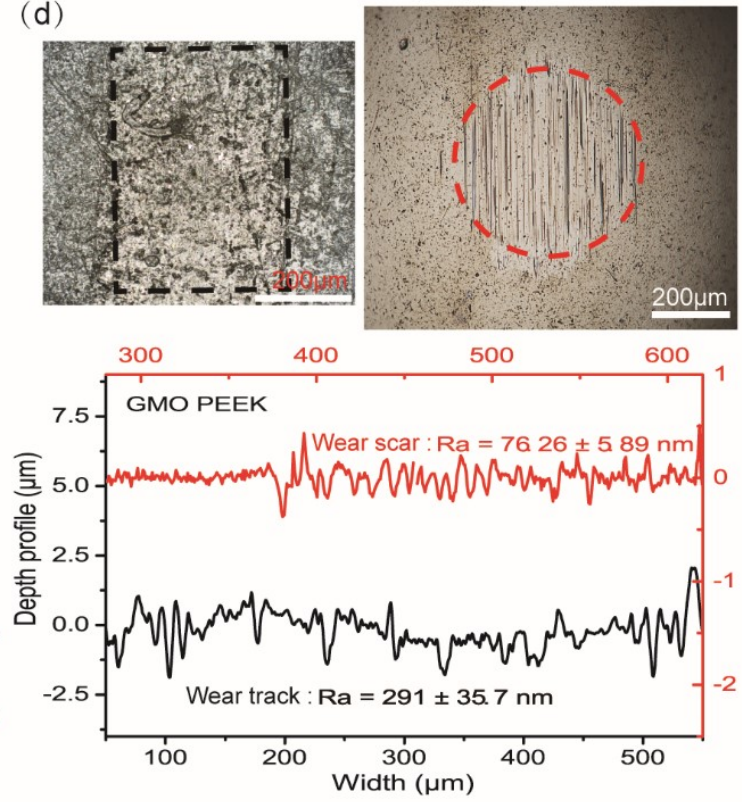

Figure 3 Optical images of wear tracks on polymer discs (black dash rectangles) and wear scars on steel balls (red dash circles) formed at an applied load of $9 \mathrm{~N}$ and their cross-section profiles (black and red for wear tracks and wear scars respectively): (a) PAI in PAO, (b) PEEK in PAO, and (c) PAI in PAO+GMO, (d) PEEK in PAO+GMO. White scale bars in 


\subsection{Friction of polymer-polymer tribo-pairs}

To test if steel is necessary for GMO to be effective, tests were conducted with polymerpolymer contacts. Figure S5-1 in SI 5 shows how friction coefficients vary during friction tests for polymer-polymer contacts. Images and cross-section profiles of wear tracks on polymer discs are presented in Figure S5-2 and Figure S5-3 respectively. Note that polymer-polymer contacts have higher composite roughness and lower contact pressures than polymer-steel contacts. Thus, no quantitative comparison in tribological performance is made between polymer-steel and polymer-polymer contacts.

\subsubsection{PEEK-PEEK contacts}

PAO lubricated PEEK-PEEK contacts (Figure S5-1a) show stable friction coefficients at $2 \mathrm{~N}$ (black) and $6 \mathrm{~N}$ (red), with steady state friction coefficients around 0.16 and 0.06 respectively. At $9 \mathrm{~N}$ (blue, Figure S5-1a), its friction coefficient alters between two values, 0.1 and 0.25 . The maximum (solid symbols) and minimum (open symbols) COFs at each applied load were shown in Figure 4 (squares), which highlights the nature of this 2-state friction observed at 9 $\mathrm{N}$.

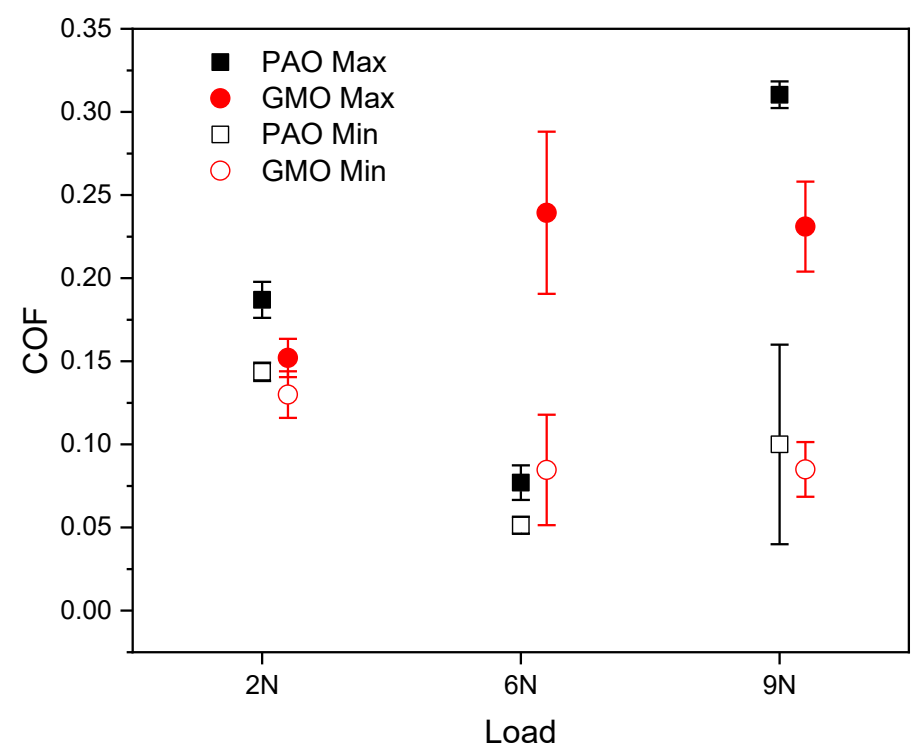

Figure 4 Maximum and minimum friction coefficients of PEEK-PEEK contacts at different loads. Results obtained in PAO+GMO (circles) are offset in the x-axis for clarity.

The addition of GMO changes the tribological performance of PEEK-PEEK contacts (Figure S5-1c and red circles in Figure 4). In PAO+GMO, the phenomenon of a 2-state friction is now seen at an applied load of 6 and $9 \mathrm{~N}$, with these contacts experience prolonged periods of high and low friction. Note that COFs of the two states obtained at both loads are similar, which suggests that the origin of their friction transitions is likely to be similar. Despite the fluctuations in friction, the minimum COFs at higher loads are lower than steady state $\mathrm{COF}$ at $2 \mathrm{~N}$ in PAO 
with or without GMO. This effect of applied load is consistent to observations with PEEK-steel contacts (see solid circles in Figure 2).

231 Origin of fluctuations in friction coefficients in PEEK-PEEK contacts is unclear. It may be associated with mechanical instabilities due to fluctuations in local temperatures. Since PEEK has poor thermal conductivity, it is possible that the local contact temperature of the PEEKPEEK contact may approach the glass transition temperature of PEEK $\left(143^{\circ} \mathrm{C}\right)$. This can cause polymer surfaces to soften, leading to a rapid drop in friction. ${ }^{37-38}$ In the meantime, the entrainment of the lubricant may provide a cooling effect. As properties of polymers near their $\mathrm{T}_{\mathrm{g}}$ are very sensitive to temperature, small contact temperature fluctuations may lead to large friction fluctuations as observed here. Based on Jaeger's model, ${ }^{39-40}$ the estimated average flash temperature rise due to shear heating reaches $83^{\circ} \mathrm{C}$ for a PAO-lubricated PEEK-PEEK contact at $9 \mathrm{~N}$ (see Table S6-2 in SI 6). This estimation however does not consider surface roughness, which may increase local temperature further. A local temperature rise can also be generated by debris entrainment. ${ }^{19}$

The friction transition with the use of OFM has been shown to be temperature dependent ${ }^{41-42}$ and is due to a change in layer structure, desorption or degradation of surface adsorbed OFM. It is possible that similar effect may be observed with load and may contribute to the effect of GMO on friction fluctuation.

\subsubsection{PAI-PAI contacts}

249 For PAO lubricated PAI-PAI contacts, friction increases with applied load (see squares in Figure 5a). This is contrary to observations with PAI-steel contacts where COF decreases with load (Figure 5b). Increasing friction with load may indicate an increase in the real contact area and hence the adhesion between the two surfaces. The strong adhesion between the two PAI surfaces explains the observed severe wear (see Figure S5-2 in SI 5), with a lot of polymer debris found in the lubricant after tests. Unlikely PEEK-PEEK contacts, the friction coefficient of the PAI-PAI contact is relatively stable at 9 N (see Figure S5-1a vs. Figure S5-1b in SI5 for PEEK-PEEK and PAI-PAI contacts respectively). This may be due to its higher glass transition temperature $\left(275^{\circ} \mathrm{C}\right)$. The use of GMO does not change the tribological performance of PAIPAI contacts substantially except at an applied load of $9 \mathrm{~N}$ where a significant reduction in friction coefficient is observed (see circles in Figure 5a). This shows that GMO is more effective 


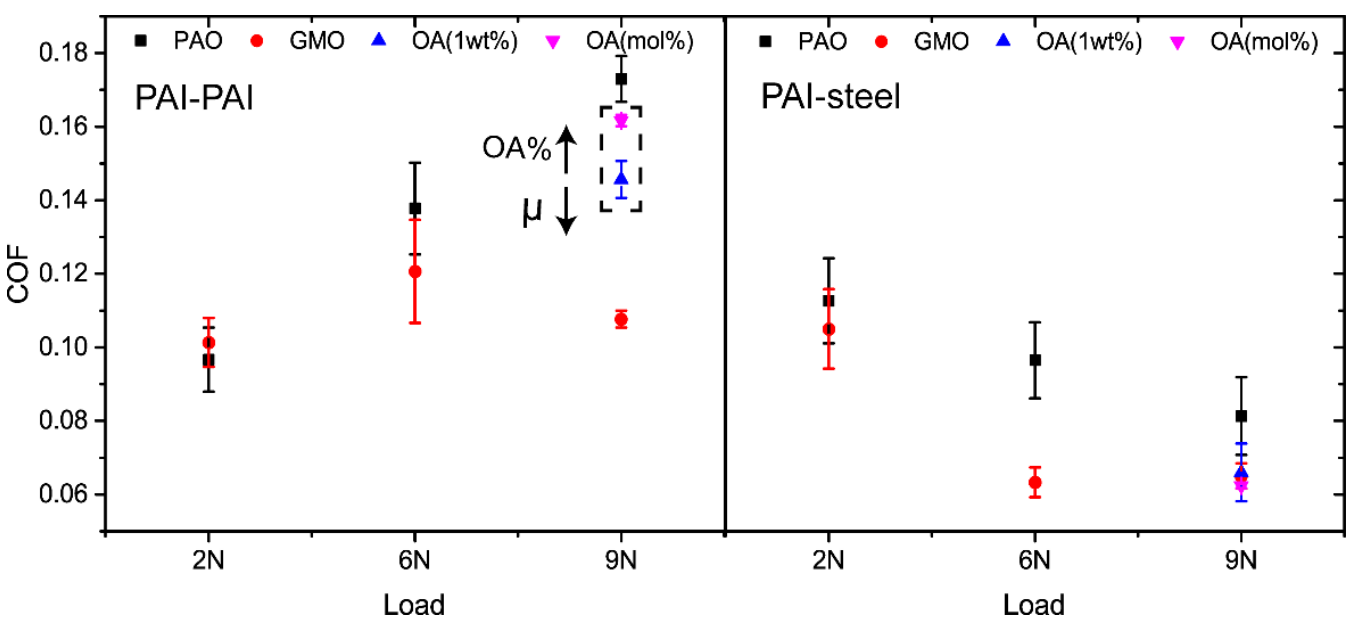

Figure. 5 Steady state friction coefficients under $\mathrm{PAO}, \mathrm{PAO}+\mathrm{GMO}$ and $\mathrm{PAO}+\mathrm{OA}$ lubrication of (a) PAI-PAI contacts, and (b) PAI-Steel contacts.

\subsection{Effect of oleic acid}

The effect of GMO in friction reduction is observed is the most significant at $6 \mathrm{~N}$ and $9 \mathrm{~N}$ for PAI-steel and PAI-PAI respectively. Since OFM is surface active, its effect is most obvious as the real contact area increases. The effectiveness of GMO may also be pressure-activated, which has been seen in other surface-active additives, such as anti-wear additives. ${ }^{4}$ Note that under the same load, the contact pressure of a PAI-steel contact is higher than PAI-PAI contacts. As a result, a friction reduction with GMO for a PAI-PAI contact may only be obvious at higher load.

The difference in the effectiveness of GMO in PAI-steel and PAI-PAI contacts may also be due to GMO interacting differently with steel and PAI. Note it is believed that GMO undergoes hydrolysis to form glycerol and oleic acid (OA) in steel-steel contacts. The resulting fatty acid monolayer on steel surfaces is responsible for improved boundary lubrication. ${ }^{43}$ Studies with a ferrous tribo-system have found that OA has lower or similar friction than GMO. ${ }^{27-28}$ Recent simulations, however, suggests that on a mica surface, a pure GMO layer has lower friction than a mixed GMO and OA layers. ${ }^{10}$ This suggests that the nature of the boundary layers formed by GMO may be surface dependent.

To investigate if the GMO boundary layer on PAI consists of OA, PAO+OA were used to lubricate PAI-PAI and PAI-steel contacts at an applied load of $9 \mathrm{~N}$ (see Figure 5). Two PAO+OA lubricants were prepared, with concentration of $0.0029 \mathrm{~mol} / \mathrm{L}(1 \mathrm{wt} \%)$ and $0.0023 \mathrm{~mol} / \mathrm{L}$. For PAI-steel contacts (Figure 5b), PAO+OA (triangles) and $\mathrm{PAO}+\mathrm{GMO}$ (circles) give similar friction coefficients. These results support that the interaction between OA, a hydrolysed product of GMO, and steel surface governs the friction reduction mechanism in PAI-steel contacts lubricated by $\mathrm{PAO}+\mathrm{GMO}$.

While OA reduces friction in PAI-PAI contacts in PAO, it is not as effective as GMO (Figure 5a). This implies that boundary layers formed in PAO+GMO on PAI is different to that on steel. The difference can be structural and/or chemical. As GMO and OA can form micelles in oil, ${ }^{5-7}$ 10 
micellar layers, rather than OFM monolayers, may form on PAI. If the hydrolysis of GMO is pressure dependent, these layers may consist of mainly GMO, rather than OA, in PAI-PAI contacts due to its lower pressure. It is also possible that OA may adsorb more weakly on PAI than on steel, giving rise to higher friction in PAI-PAI contacts.

\subsection{Analysis based on FTIR spectra}

Fourier-transform infrared spectroscopy (FTIR) spectra of wear scars on steel balls formed at an applied load of $9 \mathrm{~N}$ are presented in Figure 6. Spectra of PAO, PEEK and PAI are included for reference. Recall that PAO and PAO+GMO have similar FTIR spectra (Figure S2-1 in SI 2). Details on assignments of FTIR absorption peaks and summaries of observations are presented in Table 3.

Table 3 Peaks in FTIR spectra of steel ball wear scars (numbers in brackets suggest corresponding peaks in spectra of new PAI or PEEK samples)

\begin{tabular}{|c|c|c|c|}
\hline Counterface & $\begin{array}{l}\text { Wavenumber } \\
\left(\mathrm{cm}^{-1}\right)\end{array}$ & Peak assignments & Observations \\
\hline \multirow{6}{*}{$\begin{array}{l}\text { PAI } \quad(\text { see } \\
\text { Figure } 6 b)\end{array}$} & $3255 \mathrm{~cm}^{-1}$ & -NH stretching & In PAO: broad peak \\
\hline & Zone 1 & $\begin{array}{l}\text { Methylene linked between } \\
\text { benzenes, C-H stretching }\end{array}$ & $\begin{array}{l}\text { Polymer peaks overlap with } \\
\text { signals from PAO }\end{array}$ \\
\hline & $1744(1735)$ & $\begin{array}{l}\gamma \quad \text { lactam, } \quad \mathrm{C}=\mathrm{O} \\
\text { symmetrical stretching }\end{array}$ & $\begin{array}{l}\text { Only observed in PAO and shift } \\
\text { towards high wavenumber }\end{array}$ \\
\hline & Zone 2 & $\begin{array}{l}\gamma \text { lactam, } \mathrm{C}=\mathrm{O} \text { bending, } \\
\text { amide, } \mathrm{C}=\mathrm{O} \text { stretching }\end{array}$ & $\begin{array}{l}\text { Only observed in PAO, see peak } \\
\text { at } 1744 \mathrm{~cm}^{-1}\end{array}$ \\
\hline & 1515 & Amide, -NH bending & Only observed for neat PAI \\
\hline & Zone 4 & $\mathrm{C}-\mathrm{H}$ of phenyl rings & $\begin{array}{l}\text { In PAO and PAO+GMO: a } \\
\text { broad peak } \\
\text { In PAO+OA: Featureless }\end{array}$ \\
\hline \multirow[t]{6}{*}{$\begin{array}{l}\text { PEEK (see } \\
\text { Figure } 6 \mathrm{c})\end{array}$} & Zone 1 & $\begin{array}{l}\text { Methylene linked between } \\
\text { benzenes, C-H stretching }\end{array}$ & $\begin{array}{l}\text { Polymer peaks overlap with } \\
\text { signals from PAO }\end{array}$ \\
\hline & $1671(1661)$ & $\begin{array}{l}\text { Backbone carbonyl of } \\
\text { ketone, } \mathrm{C}=\mathrm{O} \text { stretching }\end{array}$ & $\begin{array}{l}\text { In PAO and PAO+GMO: shows } \\
\text { broadening, shifts towards high } \\
\text { wavenumber }\end{array}$ \\
\hline & $1617(1609)$ & $\begin{array}{l}\text { Skeletal in-plane vibration } \\
\text { of aromatic ring }\end{array}$ & $\begin{array}{l}\text { In PAO+GMO: shifts towards } \\
\text { high wavenumber }\end{array}$ \\
\hline & $1510(1505)$ & $\mathrm{C}=\mathrm{C}$ aromatic vibration & $\begin{array}{l}\text { In PAO+GMO: shifts towards } \\
\text { high wavenumber }\end{array}$ \\
\hline & Zone 3 & $\begin{array}{l}\mathrm{C}-\mathrm{H} \text { bending, } \mathrm{C}-\mathrm{O}-\mathrm{C} \\
\text { bending and stretching }\end{array}$ & $\begin{array}{l}\text { In PAO+GMO: shifts towards } \\
\text { high wavenumber } \\
\text { In PAO and PAO+OA: } \\
\text { featureless }\end{array}$ \\
\hline & Zone 4 & $\mathrm{C}-\mathrm{H}$ of phenyl rings & $\begin{array}{l}\text { In PAO+GMO: shifts towards } \\
\text { high wavenumber }\end{array}$ \\
\hline
\end{tabular}




\begin{tabular}{|l|l|l|l|}
\hline & & & $\begin{array}{l}\text { In PAO and PAO+OA: } \\
\text { Featureless }\end{array}$ \\
\hline \multirow{2}{*}{ PAO } & Zone 1 & Alkyl, C-H stretching & \\
\cline { 2 - 4 } & 1469,1379 & Methylene, C-H bending & \\
\hline
\end{tabular}

304

In all cases, similar spectra were obtained at different locations in steel ball wear scars. An example is given in Figure S6-1, which shows FITR spectra taken at different locations (see accompanied optical image) in a steel ball wear scar of a PAI-steel contact formed in PAO. Only spectra taken from centers of wear scars are presented hereafter. Note that the small feature at $2330 \mathrm{~cm}^{-1}$ is due to asymmetric stretch for $\mathrm{CO}_{2}$ from the ambient. ${ }^{44}$

\subsubsection{PAI-steel tribopair}

FTIR spectra taken in steel ball wear scars formed in PAO lubricated PAI-steel contacts are presented in Figure 6a (blue). Peaks around $1469 \mathrm{~cm}^{-1}$ and $1379 \mathrm{~cm}^{-1}$ are assigned to alkyl C$\mathrm{H}$ bending vibration from $\mathrm{PAO}$ and have shifted towards lower wavenumber when observed in spectra of wear scars. Peaks at $2800-3000 \mathrm{~cm}^{-1}$ (region 1) can be assigned to alkyl (C-H) stretching vibration from PAO although peaks from the methylene group situated between benzene rings in the PAI structure also occurs in this region. Signatures of PAI can be found, including a broad peak at about $3255 \mathrm{~cm}^{-1}$ (stretching -NH) from amide group. ${ }^{45}$ Peaks between $1735 \mathrm{~cm}^{-1}$ and $1500 \mathrm{~cm}^{-1}$ (zone 2) can be assigned to stretching vibration of double bond groups like $\mathrm{C}=\mathrm{C}$ and $\mathrm{C}=\mathrm{O}$. Peak of carbonyl $(\mathrm{C}=\mathrm{O})$ stretching vibration from PAI $\left(1735 \mathrm{~cm}^{-1}\right)$, which has shifted to high wavenumber to $1744 \mathrm{~cm}^{-1}$, can be observed. Generally, a peak shift towards high or low wavenumber suggests an increased or reduced degree of crystallinity due to chain scission and crosslink. ${ }^{46}$ This may be due to the high localized shear stress at asperity contacts during rubbing, leading to chain alignment and scission. High local temperature rises at asperities due to frictional heating may also contribute. Peaks in zone 4 are assigned to $\mathrm{C}-\mathrm{H}$ of phenyl rings and become a broad peak after tests. This shows PAI chains have been oxidized severely and mostly amorphous carbonaceous material remains. FTIR spectra from steel ball wear scars formed in $\mathrm{PAO}+\mathrm{GMO}$ (pink) and $\mathrm{PAO}+\mathrm{OA}$ (green) do not contain obvious peaks related to PAI. A broad peak in zone 4 is however observed in the spectrum from in $\mathrm{PAO}+\mathrm{GMO}$ which may be from highly degraded PAI. 


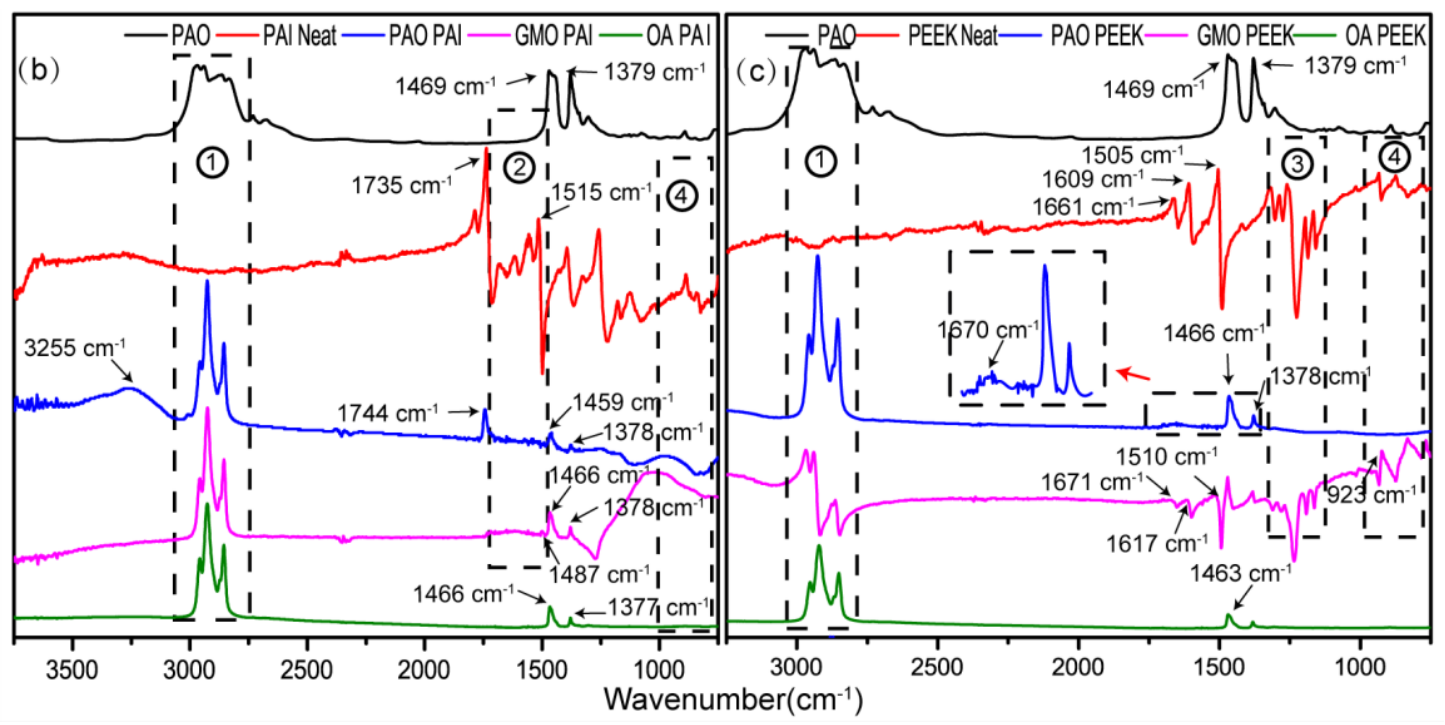

Figure 6 FTIR spectra taken at center of steel ball wear scars formed at $9 \mathrm{~N}$ of (a) PAI-steel contacts and (b) PEEK-steel contacts.

Our results support that PAI related material has been transferred to the steel counterface during rubbing in PAO. There is however insufficient evidence to support such transfer has occurred in $\mathrm{PAO}+\mathrm{GMO}$ and $\mathrm{PAO}+\mathrm{OA}$.

\subsubsection{PEEK-steel tribopair}

FTIR spectra of steel ball wear scars formed during rubbing against PEEK in PAO and PAO+GMO (blue and pink respectively, Figure 6b) show a weak peak at $1671 \mathrm{~cm}^{-1}$ which has been assigned to carbonyl $(\mathrm{C}=\mathrm{O})$ stretching vibration of the backbone carbonyl chain of PEEK. This has a higher wavenumber and is broader than that of neat PEEK $\left(1661 \mathrm{~cm}^{-1}\right.$, red). Increased intermolecular interactions, e.g. hydrogen bonding at carbonyl $(\mathrm{C}=\mathrm{O})$ may cause peaks to broaden. Chalmers also noted that some PEEK peaks are broadened as PEEK becomes amorphous (reduced crystallinity). ${ }^{47}$

The spectrum of the wear scar formed in PAO+GMO (pink) shows peaks at $1617 \mathrm{~cm}^{-1}$ and 1510 $\mathrm{cm}^{-1}$ which are attributed to skeletal in-plane and $\mathrm{C}=\mathrm{C}$ vibration of aromatic ring, respectively. Both have shifted towards higher wavenumber, which suggests an increase in crystallinity of PEEK on the transferred materials on the steel wear scar. It may also be caused by a decreased bond length due to a change in electronegativity of the neighboring atom as crosslinking occurs after bond scission. ${ }^{48}$ Additionally, peaks related to PEEK have been observed in zone 3 and zone 4, which are assigned to $\mathrm{C}-\mathrm{H}$ bending, $\mathrm{C}-\mathrm{O}-\mathrm{C}$ bending and stretching and $\mathrm{C}-\mathrm{H}$ of phenyl rings, respectively. For spectrum of steel wear scar formed in PAO+OA, no PEEK peak is evident.

Our results support that PEEK related material has been transferred to the steel counterface during rubbing in $\mathrm{PAO}$ and $\mathrm{PAO}+\mathrm{GMO}$. There is however insufficient evidence to support such transfer has occurred in $\mathrm{PAO}+\mathrm{OA}$.

Our results show that polymeric transfer layers' form on steel wear scars in PAO. In the case PEEK-steel contacts, they also form in PAO+GMO. The transfer layers, being formed under shear and friction heating, are different from the pristine polymers. Note that the use of additives 
impacts on the process of polymer transfer. OA prevents polymeric transfer on steel in both cases. GMO on the other hand may promote the transfer process in PEEK-steel contacts. This shows the interaction of steel and the OFM governs the tribological properties of polymer-steel contacts.

\subsection{Analysis based on Raman spectra}

Raman spectra of wear scars on steel balls formed by rubbing against PAI and PEEK at an applied load of $9 \mathrm{~N}$ are shown in Figure 7a and 7b. Results from steel-steel contacts are included in Figure $7 \mathrm{c}$ and discussed in SI 8 for reference. Note that common oxidation products of iron include hematite $\left(\alpha-\mathrm{Fe}_{2} \mathrm{O}_{3}\right)$, magnetite $\left(\mathrm{Fe}_{3} \mathrm{O}_{4}\right)$, wustite $(\mathrm{FeO})$, maghemite $\left(\gamma-\mathrm{Fe}_{2} \mathrm{O}_{3}\right)$, goethite $(\alpha-\mathrm{FeOOH})$, lepidocrocite $(\gamma-\mathrm{FeOOH})$ and $\delta$-FeOOH.${ }^{49}$

In a PAI-steel contact lubricated with PAO (dotted line in Figure 7a), the Raman spectrum of the steel ball wear scar show some resemblance to that of the steel-steel contact (dotted line in Figure 7c), with peaks of $\alpha-\mathrm{Fe}_{2} \mathrm{O}_{3}$ and $\gamma-\mathrm{Fe}_{2} \mathrm{O}_{3}$ overlays with peaks from the D- and G-bands of amorphous carbon. When lubricated with $\mathrm{PAO}+\mathrm{GMO}$ (dashed line), the spectrum obtained, even after amplification, shows only the D- and G- bands of amorphous carbon. The spectrum obtained from the wear scar formed in PAO+OA (solid line) only show a small broad peak centered around $800 \mathrm{~cm}^{-1}$, which also appears in that formed in PAO+GMO (dashed line). 


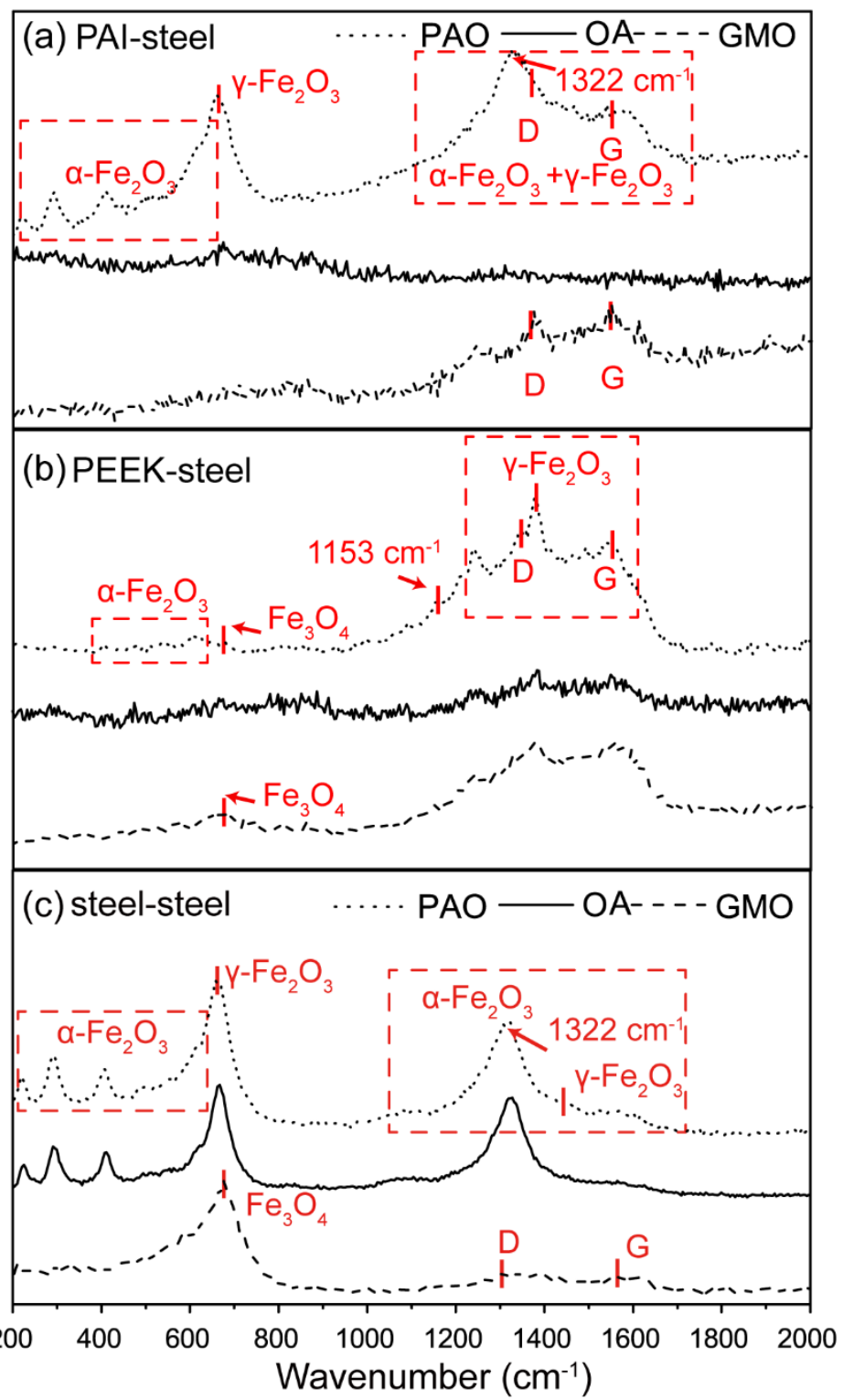

Figure. 7 Raman spectra obtained on steel ball wear scars of (a) PAI-steel contact at $9 \mathrm{~N}$, (b) PEEK-steel contact at $9 \mathrm{~N}$ and (c) steel-steel contact at $2 \mathrm{~N}$.

The spectrum of the steel ball wear scar of a PEEK-steel contact lubricated with PAO (dotted line) is shown in Figure $7 b$. It supports the existence of hematite $\left(\alpha-\mathrm{Fe}_{2} \mathrm{O}_{3}\right)$, magnetite $\left(\mathrm{Fe}_{3} \mathrm{O}_{4}\right.$ at $\left.672 \mathrm{~cm}^{-1}\right)$ and maghemite $\left(\gamma-\mathrm{Fe}_{2} \mathrm{O}_{3}\right)$. Peaks related to iron oxide below $600 \mathrm{~cm}^{-1}$ are however less distinguishable than that formed in the PAI-steel contact. The use of OA (solid line) and GMO (dashed line) results in the removal of iron oxidation related peaks in the Raman spectra, like what is observed in PAI-steel contacts.

Our results show that when lubricating PAI-steel and PEEK-steel contacts with PAO, the steel counterface undergoes similar oxidation process to that observed in steel-steel contacts. In additions, some amorphous carbon is found. This is likely due to polymeric transfer materials. D- and G-bands of amorphous carbon may also come from the degradation of PAO. This is unlikely however as these peaks are not observed in the case of steel-steel contacts, where PAO was subjected to higher stress than in polymer-steel contacts. 
When additives are used, Raman spectra of the steel ball wear scars lack features of oxidation products of iron and the intensities of D- and G-bands are substantially reduced. It is known that GMO and OA can form a boundary layer on steel. ${ }^{50-51}$ These OFM boundary layers may protect the steel counterface from oxidation in a polymer-steel contact by forming a physical barrier. The reduction in friction due to the use of OFM also reduces frictional heating. Based on the results from FTIR, the OFM layers also limit polymer transfer onto steel.

\section{CONCLUSION}

For polymers to be used more widely in engineering applications, their compatibility with existing engineering practices must be scrutinized. In this study, compatibility of two high performance polymers, PEEK and PAI, with GMO, a commonly used organic friction modifiers for lubricating steel-steel contacts, were investigated.

Our results show that adding GMO into a PAO base oil can reduce friction in both polymersteel contacts and polymer-polymer contacts. It is however more effective in polymer-steel contacts. GMO and oleic acids (OA) give similar friction coefficients in polymer-steel contacts, suggesting that the interaction of OFM with steel dominates in these contacts. OA gives higher friction than GMO in polymer-polymer contacts implies that GMO interacts with polymer and steel differently. This suggests that GMO may not form OA through hydrolysis during rubbing, as commonly hypothesized in steel-steel contacts. OA may also adhere more weakly on polymer than on steel. More work is necessary to understand the nature of OFM-polymer interactions.

Table 4 Summary of observations from FTIR and Raman spectroscopies of steel ball wear scars

\begin{tabular}{|c|c|c|c|c|}
\hline Lubricant & & PEEK-steel & PAI-steel & Interpretations \\
\hline \multirow[b]{2}{*}{ PAO } & FTIR & $\begin{array}{l}\text { PEEK-related } \\
\text { materials found }\end{array}$ & $\begin{array}{l}\text { PAI-related materials } \\
\text { found }\end{array}$ & \multirow{2}{*}{$\begin{array}{l}\text { Heterogeneous } \\
\text { polymer transfer } \\
\text { layers formed in } \\
\text { both contacts }\end{array}$} \\
\hline & Raman & $\begin{array}{l}\text { Oxidation products of } \\
\text { iron }+ \text { D- and G- } \\
\text { bands of amorphous } \\
\text { carbon }\end{array}$ & $\begin{array}{l}\text { Oxidation products of } \\
\text { iron }+\mathrm{D} \text { - and } \mathrm{G} \text { - bands of } \\
\text { amorphous carbon }\end{array}$ & \\
\hline \multirow[b]{2}{*}{ PAO+GMO } & FTIR & $\begin{array}{l}\text { PEEK-related } \\
\text { materials found }\end{array}$ & No PAI evident & \multirow{2}{*}{$\begin{array}{l}\text { GMO boundary } \\
\text { film formed. } \\
\text { PEEK transfer } \\
\text { layers may have } \\
\text { formed. }\end{array}$} \\
\hline & Raman & $\begin{array}{l}\text { Weak D- and G- } \\
\text { bands of amorphous } \\
\text { carbon }\end{array}$ & $\begin{array}{l}\text { Weak D- and G- bands of } \\
\text { amorphous carbon }\end{array}$ & \\
\hline \multirow{2}{*}{ PAO+OA } & FTIR & No PEEK evident & No PAI evident & \multirow{2}{*}{$\begin{array}{l}\text { OA tribofilm } \\
\text { formed. }\end{array}$} \\
\hline & Raman & $\begin{array}{l}\text { Weak D- and G- } \\
\text { bands of amorphous }\end{array}$ & Weak D- and G- bands of & \\
\hline
\end{tabular}




\begin{tabular}{|l|l|l|l|l|}
\hline & carbon & amorphous carbon & \\
\hline
\end{tabular}

The use of OFM affects the formation of polymeric transfer layer and oxidation on steel counterfaces in polymer-steel contacts. A summary of observations from FTIR and Raman spectroscopies of steel ball wear scars is presented in Table 4. Our results show that polymeric transfer occurs in PAO. The transfer layer may have different crystallinity and chemistry to those of the neat polymers due to the shear stress and frictional heating in rubbing contacts. This is consistent to what has been observed under dry condition. Note this polymeric layer does not prevent steel counterface from oxidation during rubbing.

The use of OFMs suppresses polymeric transfer and iron oxide formation on steel. Their use also results in rougher steel surfaces. Both GMO and OA are known to form OFM layers on steel readily due to their polar head groups. These OFM layers may prevent polymer transfer and protect steel from oxidation. The OFM may also adsorb on surface cracks, promote crack growth and hence resulting in rougher surface. Its low shear strength allows low friction to be maintained despite the rough wear surface. Note that in dry polymer-steel rubbing contacts, the existence of polymeric transfer layers on steel counterfaces is often crucial for achieving stable low friction. The use of OFMs which strongly interact with steel alleviates the dependence of polymeric transfer film for low friction. This allows polymer to be used in lubricated contact against counterfaces which may consider not viable in dry conditions.

\section{ACKNOWLEDGEMENTS}

S.J. is supported by the Fundamental Research Funds for the Central Universities of China. The authors would be like to thank Carlos E Garcia and Debashis Puhan for the help with Raman spectroscopy. Polymer samples were kindly donated by Hoerbiger and Victrex.

\section{REFERENCES}

(1) Holmberg, K. ; Erdemir, A. Influence of tribology on global energy consumption, costs and emissions. Friction 2017, 5 (3), 263-284, D0I: 10. 1007/s40544-017-0183-5.

(2) Spikes, H. Friction Modifier Additives. Tribology Letters 2015, 60 (1), 5, D0I: 10. 1007/s11249-015-0589-z.

(3) Bowden, F. P. ; Gregory, J. N. ; Tabor, D. Lubrication of Metal Surfaces by Fatty Acids. Nature 1945, 156 (3952), 97-101, D0I: 10.1038/156097a0.

(4) Zhang, J. ; Spikes, H. On the Mechanism of ZDDP Antiwear Film Formation. Tribology Letters 2016, 63 (2), 24, D0I: 10. 1007/s11249-016-0706-7.

(5) Tsagkaropoulou, G. ; Warrens, C. P. ; Camp, P. J. Interactions between Friction Modifiers and Dispersants in Lubricants: The Case of Glycerol Monooleate and 
Polyisobutylsuccinimide-Polyamine. ACS Applied Materials \& Interfaces 2019, 11 (31), 28359-28369, DOI: 10. 1021/acsami. 9b05718.

(6) Bradley-Shaw, J. L. ; Camp, P. J. ; Dowding, P. J. ; Lewtas, K. Self-assembly and friction of glycerol monooleate and its hydrolysis products in bulk and confined non-aqueous solvents. Physical Chemistry Chemical Physics 2018, 20 (26), 17648-17657, D0I: 10. 1039/C8CP01785A.

(7) Bradley-Shaw, J. L. ; Camp, P. J. ; Dowding, P. J. ; Lewtas, K. Glycerol Monooleate Reverse Micelles in Nonpolar Solvents: Computer Simulations and Small-Angle Neutron Scattering. The Journal of Physical Chemistry B 2015, 119 (11), 4321-4331, D0I: 10. 1021/acs. jpcb. 5b00213.

(8) Kim, D. -W. ; Kim, K. -W. Tribological characteristics of $\mathrm{Cr} / \mathrm{CrN} / \mathrm{a}-\mathrm{C}: \mathrm{H}: \mathrm{W} / \mathrm{a}-\mathrm{C}: \mathrm{H}$ coating under boundary lubrication conditions with glycerol mono-oleate (GMO) and molybdenum dithiocarbamate (MoDTC). Wear 2015, 342-343, 107-116, D0I: https://doi. org/10. 1016/j. wear. 2015. 08. 011.

(9) Kano, M. ; Yasuda, Y. ; Okamoto, Y. ; Mabuchi, Y. ; Hamada, T. ; Ueno, T. ; Ye, J. ; Konishi, S. ; Takeshima, S. ; Martin, J. M. ; De Barros Bouchet, M. I. ; Mognee, T. L. Ultralow friction of DLC in presence of glycerol mono-oleate (GNO). Tribology Letters 2005, 18 (2), 245-251, DOI: 10. 1007/s11249-004-2749-4.

(10) Unal, H. ; Kurt, M. ; Mimaroglu, A., Tribological performance of industrial polyamide-imide and its composite under different cooling conditions. In Journal of Polymer Engineering, 2012; Vol. 32, p 201.

(11) Friedrich, K. ; Reinicke, P. Friction and wear of polymer-based composites. Mechanics of Composite Materials 1998, 34 (6), 503-514.

(12) Holtzberg, M., Internal combustion engine block and cylinder head. US Patent $4848292,1989$.

(13) Holtzberg, M. W. ; Henke, S. J; Spaulding, L. D. ; Oakley, J. C. Composite piston ring and process. US Patent:4432925, 1984.

(14) Holtzberg, M. W. ; Cole, B. W., Composite connecting rod and process. US Patent:4458555, 1984.

(15) Jean-Fulcrand, A. ; Masen, M. A. ; Bremner, T. ; Wong, J. S. High temperature tribological properties of polybenzimidazole (PBI). Polymer 2017, 128, 159-168.

(16) Puhan, D. ; Wong, J. S. S. Properties of Polyetheretherketone (PEEK) transferred materials in a PEEK-steel contact. Tribology International 2019, 135, 189-199, DOI: https://doi. org/10. 1016/j. triboint. 2019. 02. 028.

(17) Ünal, H. ; Kurt, M. ; Mimaroglu, A. Tribological performance of industrial polyamide-imide and its composite under different cooling conditions. Journal of Polymer Engineering 2012, 32, DOI: 10. 1515/polyeng-2011-0156.

(18) Unal, H. ; Findik, F. Friction and wear behaviours of some industrial polyamides against different polymer counterparts under dry conditions. Industrial Lubrication and Tribology 2008, 60 (4), 195-200, DOI: 10.1108/00368790810881542.

(19) Shen, C. ; Khonsari, M. M. ; Spadafora, M. ; Ludlow, C. Tribological Performance of Polyamide-Imide Seal Ring Under Seawater Lubrication. Tribology Letters 2016, 62 (3), 39, DOI: 10. 1007/s11249-016-0686-7.

(20) Laux, K. ; Jean-Fulcrand, A. ; Sue, H. ; Bremner, T. ; Wong, J. The influence of 
surface properties on sliding contact temperature and friction for polyetheretherketone (PEEK). Polymer 2016, 103, 397-404.

504 (21) Liu, C. ; Wu, J. ; Li, J. ; Ren, L. ; Tong, J. ; Arnell, A. Tribological behaviours of PA/UHMWPE blend under dry and lubricating condition. Wear 2006, 260 (1-2), 109-

$506 \quad 115$

507 (22) Zhou, J. ; Blair, B. ; Argires, J. ; Pitsch, D. Experimental performance study of 508 a high speed oil lubricated polymer thrust bearing. Lubricants 2015, 3 (1), 3-13.

509 (23) Zhang, G. ; Wetzel, B. ; Wang, Q. Tribological behavior of PEEK-based materials 510 under mixed and boundary lubrication conditions. Tribology International 2015, 88, $511 \quad 153-161$.

512 (24) Zhang, Z. -Z. ; Shen, W. -C. ; Liu, W.-M. ; Xue, Q. -J. ; Li, T.-S. Tribological 513 properties of polytetrafluoroethylene-based composite in different lubricant media. 514 Wear 1996, $196(1-2), 164-170$.

515 (25) Hamrock, B. J. ; Dowson, D. Isothermal elastohydrodynamic lubrication of point 516 contacts: part III-fully flooded results. 1977.

517 (26) Bombard, A. ; Gonçalves, F. ; Shahrivar, K. ; Ortiz, A. ; De Vicente, J. Tribological 518 behavior of ionic liquid-based magnetorheological fluids in steel and polymeric point 519 contacts. Tribology International 2015, 81, 309-320.

520 (27) Murase, A. ; Ohmori, T. ToF - SIMS analysis of model compounds of friction modifier 521 adsorbed onto friction surfaces of ferrous materials. Surface and Interface Analysis:

522 An International Journal devoted to the development and application of techniques 523 for the analysis of surfaces, interfaces and thin films 2001, 31 (3), 191-199.

524 (28) Koshima, H. ; Kamano, H. ; Hisaeda, Y. ; Liu, H. ; Ye, S. Analyses of the adsorption 525 structures of friction modifiers by means of quantitative structure-property 526 relationship method and sum frequency generation spectroscopy. Tribology Online 2010, $527 \quad 5(3), 165-172$.

528 (29) Wen, S. ; Huang, P. Principles of tribology, John Wiley \& Sons: 2012.

529 (30) Hu, X. Friction and wear behaviors of toughened polyoxymethylene blend under 530 water lubrication. Polymer-plastics technology and engineering 2000, 39 (1), 137531150.

532 (31) Unal, H. ; Mimaroglu, A. Friction and wear characteristics of PEEK and its 533 composite under water lubrication. Journal of reinforced plastics and composites $5342006,25(16), \quad 1659-1667$.

535 (32) Samyn, P. ; Schoukens, G. Experimental extrapolation model for friction and wear 536 of polymers on different testing scales. International Journal of Mechanical Sciences $5372008,50(9), \quad 1390-1403$.

538 (33) Yamaguchi, Y. Tribology of plastic materials: their characteristics and 539 applications to sliding components, Elsevier: 1990; Vol. 16.

540 (34) Pascoe, M. ; Tabor, D. The friction and deformation of polymers. Proceedings of 541 the Royal Society of London. Series A. Mathematical and Physical Sciences 1956, 235 542 (1201), 210-224.

543 (35) Fry, B. M. ; Moody, G. ; Spikes, H. A. ; Wong, J. S. Adsorption of Organic Friction 544 Modifier Additives. Langmuir 2020.

545 (36) Wen, S. ; Huang, P. Principles of Tribology. Production Engineer 2011, 54 (12), 
647-648.

547 (37) Cheng, S. Z. ; Cao, M. ; Wunderlich, B. Glass transition and melting behavior of

548 poly (oxy-1, 4-phenyleneoxy-1, 4-phenylenecarbonyl-1, 4-phenylene) (PEEK).

549 Macromolecules 1986, 19 (7), 1868-1876.

550 (38) Ettles, C. M. McC. Polymer and elastomer friction in the thermal control regime.

551 ASLE transactions 1987, 30 (2), 149-159.

552 (39) Jaeger, J. C. In Moving sources of heat and the temperature of sliding contacts, 553 Proceedings of the royal society of New South Wales, 1942; pp 203-224.

554 (40) Jean-Fulcrand, A. ; Masen, M. A. ; Bremner, T. ; Wong, J. S. S. Effect of

555 temperature on tribological performance of polyetheretherketone-polybenzimidazole

556 blend. Tribology International 2019, 129, 5-15, DOI:

557 https://doi. org/10.1016/j. triboint. 2018.08.001.

558 (41) Frewing, J. J. ; Rideal, E. K. The heat of adsorption of long-chain compounds 559 and their effect on boundary lubrication. Proceedings of the Royal Society of London.

560 Series A. Mathematical and Physical Sciences 1944, 182 (990), 270-285.

561 (42) Frewing, J. J. ; Taylor, G. I. The influence of temperature on boundary 562 lubrication. Proceedings of the Royal Society of London. Series A. Mathematical and 563 Physical Sciences 1942, 181 (984), 23-42, DOI: doi:10. 1098/rspa. 1942. 0056.

564 (43) Frewing, J. J. ; Rideal, E. K. The heat of adsorption of long-chain compounds 565 and their effect on boundary lubrication. Proceedings of the Royal Society of London.

566 Series A. Mathematical and Physical Sciences 1944, 182 (990), 270-285.

567 (44) Moore, G. ; Chizmeshya, A. ; McMillan, P. F. Calibration of a reflectance FTIR 568 method for determination of dissolved $\mathrm{C} 02$ concentration in rhyolitic glasses. 569 Geochimica et Cosmochimica Acta 2000, 64 (20), 3571-3579.

570 (45) Mallakpour, S. ; Zadehnazari, A. Molten salt-supported polycondensation of 571 optically active diacid monomers with an aromatic thiazole-bearing diamine using 572 microwave irradiation. Journal of advanced research 2014, 5 (3), 311-318.

573 (46) Chen, Z.; Hay, J. N. ; Jenkins, M. J. FTIR spectroscopic analysis of poly (ethylene 574 terephthalate) on crystallization. European Polymer Journal 2012, 48 (9), 1586-1610, 575 D0I: https://doi. org/10. 1016/j. eurpolymj. 2012.06. 006.

576 (47) Chalmers, J. ; Gaskin, W. ; Mackenzie, M. Crystallinity in poly (aryl-ether577 ketone) plaques studied by multiple internal reflection spectroscopy. Polymer 578 Bulletin 1984, 11 (5), 433-435.

579 (48) Gordy, W. A relation between bond force constants, bond orders, bond lengths, 580 and the electronegativities of the bonded atoms. The Journal of Chemical Physics 581 1946, 14 (5), 305-320.

582 (49) de Faria, D, L. A; Venâncio Silva, S, ; de Oliveira, M, T. Raman microspectroscopy 583 of some iron oxides and oxyhydroxides. Journal of Raman Spectroscopy 1997, 28 (11), $584 \quad 873-878$.

585 (50) Langmuir, I. The mechanism of the surface phenomena of flotation. Trans Faraday 586 Soc 1920, 15 (June), 62-74.

587 (51) Beltzer, M. ; Jahanmir, S. Effect of additive molecular structure on friction. 588 Lubrication Science 1988, 1 (1), 3-26, DOI: 10.1002/1s. 3010010103. 